Distr.: LIMITED

ECA/NRD/CART.9/ORG.12

October 1996

Original: ENGLISH

\author{
Ninth United Nations Regional \\ Cartographic Conference for Africa \\ Addis Ababa, Ethiopia \\ 11-15 November 1996
}

\title{
INTERNATIONAL CARTOGRAPHIC ASSOCIATION
}

PROGRESS DURING 1991-95 


\title{
International Cartographic Association - Progress during 1991-95 Michael Wood
}

\begin{abstract}
This paper is based on the recent ICA publication "The Aohievements of the ICA, 1991-95". It reviews some of the background of the organisation and concentrates on the recent activities of the Commissions and Working Groups.
\end{abstract}

\section{INTRODUCTION}

The International Cartographic Association, the world body for cartography, has been in existence for over 36 years and its broad aims are : to contribute to the understanding and solution of worldwide problems through the use of cartography in decision-making processes ; to foster the international dissemination of environmental, economic, social and spatial information through mapping ; to provide a global forum for discussion of the role and status of cartography ; to facilitate the transfer of new cartographic technology and knowledge between nations, especially to the developing nations : to carry out or to promote multi-national cartographic research in order to solve scientific and applied problems; to enhance cartographic education in the broadest sense through publications, seminars and conferences; to promote the use of professional and technical standards in cartography. Since its foundation in 1959 the list of member nations has grown from 13 to 80 with 12 affiliate organisations. Its main scientific work is done by Commissions and Working Groups. In 1995 these sections, comprising 250 individuals drawn from 66 countries, were active in 16 subject fields which are described below, In addition to accounts in the ICA Newsletter, their accomplishments are typically recorded through limited circulation reports and proceedings. There is also an established and expanding publication programme under the Pergamon/Elsevier banner. Active links of many kinds with a range of leading international organisations, such as the United Nations, have helped raise the profile and extend the reach and influence of the ICA across the wortd.

A special relationship has been established with UNICEF following the untimely death of vicepresident Barbara Petchenik, in 1992. The Children's Map Design Competition, an award set up in her memory, has been helping to unite the ICA world in a new and exciting way and the importance of this award has also been recognised as a salute to the United Nations in its 50th Anniversary Year.

The ICA faces major challenges as we approach the next millennium, but as environmental and societal problems increase in magnitude and complexity so have the power and potential of digital maps to contribute to their solution. Ideas based on new technology (e.g. GIS) and increasing knowledge of how maps are perceived, used and understood, are being co-ordinated by workers within the ICA to help tackle world-wide problems. The meetings and output of ICA workers have been publicised in various ways over the years, and in 1994, the Executive Committee decided to raise awareness of these activities. A booklet entitled "The Achievements of the ICA, 1991-95" was compiled to help inform both the membership and, where possible, the wider community.

\section{ROOTS AND VISIONS - past, present and future}

The ICA pays special attention to fundamentals, including history, map use and the theoretical basis of the subject. Current activities of the Standing Commission on the History of Cartography have focused on the publication of an international bibliography of map makers and map producing firms. Collected on a national basis the bibliography will provide a fascinating and valuable resource for researchers and collectors alike, adding to the Commission's previously acclaimed work on the Teaching of the History of Cartography. A successful seminar took place in Chicago (1993) co-organised with the Commission on Education and Training.

The actual employment of maps has been the focus of the Commission on Map and Spatial Data 
Use in which initial challenges included identification and examination of the characteristics of map use. A matrix of map-and-spatial-data-use typology is being developed with an accompanying bibliography keyed to the various 'use' dimensions. Related but important aspects of this commission's activities have been the organisational or supportive contributions made at major national and international meetings, including the Joint-Commission Seminar on Electronic Atlases, Visegrad, Hungary, 1993 ; a Technical Session on Electronic Atlases, at the American Congress on Surveying and Mapping Conference, USA, 1994 ; a Session on Map Use, at the Association of American Geographers Conference. USA, 1995 ; and the ICA Joint-Commission Seminar on Animation in Cartographic Education, in Spain, 1995. Perhaps one of the most significamt legacies of this Commission has been its part in the development of the new concept of Cartographic Visualization: these ideas surfaced at a special meeting held at the international Cartographic Conference in Cologne, 1993, which stimulated the important ICA publication. 'Visualization in Modem Cartography. This success has led to the establishment of a separate Commission to take the subject forward into the next session.

The Working Group to Define the Main Theoretical Issues on Cartography selected five guiding topics on which their studies would be based. namely map function, spatial processes, social context, processing digital data ${ }_{t}$ and map language. These were offered in outline to the ICA Newsletter in 1992 and the final report. "The Selected Main Theoretical /ssues Facing Cartography" was presented at the ICA Conference in Cologne, 1993. The Group's more recent activities have included publication of the report and questionnaire in Cartographica 30(4), 1993, and in the Joumal of the Japanese Cartographer's Association, with a summary appearing in other selected journals and also distribution of the questionnaire to many countries. The work of this group: reported in a special session at the Barcelona Conference (1995), has also led to the establishment of a full Commission for the period 1995-99.

\section{SPATIAL DATA - quality, transfer and marketing}

Data quality has always been of importance in mapping science but in the past it was generally a characteristic of the basic hardcopy map itself. Today, the concept of a 'map' has broadened to include what are now known as virtual maps, ranging from ephemeral screen displays to spatial databases themselves. In a future which will depend increasingly on the deep structure of spatial data the digital-datebase will become the bearer of quality, placing great responsibilities on those who must establish, maintain, transfer and, indeed, market data, especially at a time when such data is increasing in quantity and level of usage. The Commission on Spatial Data Quality has been examining these issues in the belief that the quality of spatial data

- is very important as large databases are created for access, exchange, and use by mamy individuals ;

- should be assessed and reported as part of each spatial data file of information ;

- should be made known to the consumer of any analysis using spatial data.

This small but active group has been exploring the basic elements of their chosen theme to provide cartographers with comprehensive definitions of those elements. Seven have been agreed, namely Lineage, Positional Accuracy, Attribute Accuracy, Completeness, Logical Consistency: Semantic Accuracy, and Temporal Accuracy; and its main accomplishment has been the publication of an Elsevier book. in October 1995, containing the required definitions. This provides a sound basis for further research into the display of data quality and reliability which will be made in conjunction with those studying Cartographic Visualisation.

The Commission on Standards for the Transfer of Spatial Data has an equally important and perhaps more urgent brief. It was first necessary to examine information from ICA member nations and from other relevant bodies, on the development of such standards. Study of the published standards of ICA member countries has also been important in these preliminary investigations. Assessment characteristics of transfer standards have been developed, refined and tested and technical presentations made at the ICA International Conference in Cologne, 1993. The first main aohievement was an ICA Report (June, 1994) entitled "Technical 
Characteristics for Assessing Standards for the Transfer of Spatial Data and Erief Intemational Descriptions" in which the standards from twenty-three countries are described. A significant, byproduct of this ICA work has been a request that the Commission serve as an International Standards Organisation (ISO) category A Scientific Liaison to ISO TC211. Technical Committee on Geographic Information/Geomatics.

As spatial data is now a tradable commodity within national and international economies the Working Group on Marketing Geographic Information has been investigating perceived barriers to the marketing process. A drat charter on the topic entitled 'Common Responses to Common Challenges' has been prepared which recognises the need for both a balanced approach to the subject and a response to the growth of private sector capacity to develop Geographical Information. It is designed to meet the needs of Cartographic Organisations, private and public, and adopts a terminology synchronous with the language of the private sector. In particular the charter sets out a series of guidelines under the headings, Data Quality and Integration, Copyright, Royalties and Licensing, and Rights and Responsibilities. The subject is far from simple but over time a set of guidelines such as these will allow common responses to many if not all of the common challenges being faced.

\section{MAP COMPILATION \& PRODUCTION - continuing challenges and Opportunities}

The methods of map production have been in a state of transition over recent years as have the nature and sources of the information contained in maps. The ICA's responsibility covers a spectrum of international practice which includes promotion of the best of tracitional (analogue) methods while facing the challenges presented by new digital technology. Such concerns heve overarching characteristics and are difficult to compartmentalise but three Commissions have been examining core factors within the subject area.

Remote Sensing has contributed much to the advancement of mapping science and this field has been the focus of the ICA Commission on Thematic Mapping from Satellite Data. The expanding manufacture of tools for image processing, the increasing adoption of GIS and also the multiplication and diversiffcation of civilian space programmes for ground observation are key elements in this revolution. Only a fraction of the available imagery is currently being utilised but changes through technology are due during the next five years. Progress in the use of satellite imagery in GIS highlights the need to distinguish between aspects relating to data and to information for the different dimensions of the cartographic message (geometric and semantic). Perhaps the Commission's three most outstanding achievements, reflecting the above idees, have been :

- "La telédétection aux fins de la cartographie topographique et thematique", their ICA contribution to the Fifth United Nations Cartographic Conference for the Americas.

- "Guide Book for Thematic Mapping from Satellite Imagery", a major work of reference.

- The international symposium "Des images satellites pour la cartographie et les systemes d'information geographique", organised in Tunis with the support of CNT (Centre National de Telédetection) in 1993. The proceedings were published as Bulletin No.142-143 of the Comite Français de Cartographie (1995).

One of the greatest challenges to digital cartographers, that of automating the map generalisation process, was taken up on behalf of the ICA by a section within the Standing Commission on Advanced Technology. The first important achievement of this working sub-group on Map Generalisation was the establishment of active links between experts and organisations from many countries. More formal involvement has occurred:

- Specialist Meeting of the NCGIA Initiative 8 "Formalizing Cartographic Knowledge", USA 1993.

- ESF GISDATA Symposium on Generalization, France 1993

Howaver, in contrast with most of these organisations, the ICA takes a more international approach and pursues a longer term strategy. A pre-conference Workstop was organised on Progress in Automated Generalization of Spatial Data (1-3 September 1995), in addition to 
regular events at ICA conferences in 1993 and 1995. The manuscript stage of a Special MapGeneralization Issue of Cartography and Geographic information Systems (publication, January 1996) has aiso been completed.

The origins of the Standing Commission on Map Production Technology lie in analogue mapping, as characterised in its textbook "Compendium of Cartographic Techniques" (1988). Although digital techniques are displacing many of the traditional there is still sufficient market to warrant a second edition of this text. However it will be in two volumes, with the second devoted to digital techniques. The revised manuscript of Volume I, with new chapters on colour systems and special cartographic products, should appear by the end of 1995 . Volume 11 will be tackled during the next session. Another important project: an oveview of technologies used for map production and reproduction world-wide, is also in press. The third achievement of this session has been the preparation and agreement on a standard symbolisation for both analogue and digital production flow diagrams. The scheme has been discussed widely and has already been introduced by some ICA member countries into their own operations. Details are included in Volume I of the new edition of the Compendium text. As this Commission is concerned with practical matters, workshops on map production took place in Zurich, Switzerland, 1992 ; Cologne, Germany, 1993, and Prague, Czech Republic, 1994. However, perhaps one of the most memorable events of this session was the collaborative Seminar with the Standing Commission on Education and Training and the Working Group on Gender and Cartography: on "Teaching Map Production Lines and Digital Cartography", Istanbul, Turkey. 1994.

\section{MAPS ARE CHANGING - design and innovation}

Athough paper maps are unlikely to disappear completely from the cartographic scene in the near future, 'new maps are already taking over in many important map using and decisionmaking situations. Animated and interactive virtual maps with additional undreamed-of dimensions are currently in use or under development, and the ICA is playing its part.

Two sub-groups of the Standing Commission on Advanced Technology are already involved in these developments. The first, Multimedia Applications for Cartography, represents one of the most exciting areas of advancement into the cartography of tomorrow. Research is under way but future plans will focus more sharply on specific projects to accelerate expansion of the field within the ICA. The second, Time in Cartography, has focused its research activities on the organisation of sessions linked to various international conferences, notably GIS/LIS '92, San Jose, USA, 1992 ; 16th ICC, Cologne, Germary, 1993 ; GIS/LIS '93, Minneapolis, USA, 1993 ; Spatial Data Handling Conference, Edinburgh, Scottand, 1994.

A two-day pre-conference event took place in Delft, Netherlands, just before the Conference in Cologne in 1993, and a similar joint three-day session before the start of the ICA General Assembly in Barcelona in September 1995. The latter benefited from interaction with the Standing Commission on Education and Training, the Commission on Map and Spatial Data Use and the sub-group on Multimedia Applications. The Time group's special contribution here was "Temporal aspects in animated cartography".

Protection and improvement of the environment is one of today's major tasks. Environmental monitoring requires a global sampling framework the changing data from which must be displayed and analysed on maps of various kinds, many of them innovative in character. One recent example of ICA involvement in such work was the international conference organised by the Commission on Advanced Technology in Warszawa, Poland, 1994. This meeting, entitled 'GIS in Ecological Studies and Environmental Management' was also sponsored by the United Nations.

The national atlas genre. still less than a century old, has undergone many changes in content and structure. In recent years it has been one of the test-beds for the application of new technologies such as multimedia. During the current ICA session the Commission on National and Regional Atlases has included such advances in its work plan and the main part of the first seminar (Madrid, 1992) was devoted to electronic atlases. A decision of that meeting was to 
investigate the current production, costs and marketing of national and regional atlases in member countries, and the results were reported to the ICA International Conference in Cologne (1993). 1993 was also the year of a seminar focused on the production, teaching and use of electronic atlases: the published proceedings of that meeting have proved to be of tremendous value as a source on the subject.

The promotion of regional electronic atlases in North America was discussed in a special session at the 1994 ACSM/ASPRS Annual Conference in Reno, Nevada. A new kind of electronic atlas, involving CDs and thematic datasets on the Internet. was discussed but could only become possible through standardisation and national strategies allowing access to the appropriate data. The proceedings are widely available in a special issue of Cartographic Perspectives (Winter, 1995).

INTERNATIONAL OUTREACH - education, equality and special needs

Although every Commission and Working Group is involved in outreach, through distant networking and the organisation of meetings world-wide, some have special missions with broader appeals.

The theme of the Standing Commission on Education and Training might be described as spreading knowledge of and respect for, cartography in all its manifestations through the process of teaching. One of its most widely appreciated contributions has been as an initiator and an integrator of its educational activities with those of other ICA Commissions and Working Groups. The seminars can be classified as follows:

- for cartographers from developing countries: "Teaching Map Production Lines and Digital Cartography", Istanbul, 1994 (the finst international cartographic event in that region of the Wortd) : "Digital Cartography and GIS", Bangkok, 1994 (an achievement in its local impact as well as the diversity and dedication of the international teaching team) :

- "New frontier" seminars for gathering new material for "Basic Cartography" texts : "Surveying and Mapping Aspects of Visualization and GIS", Washington. 1992 ; "Electronic Atlases", Visegrad, 1994 ; "Animated Cartography": Madrid, 1995.

Proceedings are available of the meetings in Budapest (1991), Uppsala (1992), Washington (1992), Visegrad (1993), Chicago (1993), Istanbul (1994) and Bangkok (1994). One of the most important on-going achievements of this Commission has been the textbook series "Basic Cartography". The Second Edition of Volume I was revised and published in 1993 and Volume III has been published in 1996.

Through its energetic and constructive outreach programme this Commission is one of the leading promoters and publicists of the ICA throughout the Worid.

Continuing the global theme the goal of the Working Group on Gender and Cartography is to promote equality of opportunity in all organisational units and at all levels of responsibility within the ICA and its member countries. Specifically this inciudes the present status of women and other under-represented groups such as younger cartographers or cartographers from developing countries. Other plans are to achieve more balanced contributions by gender, age group and geographical region and to study the impact of technological change and societal development on the cartographic profession. A number of significant achievements reflect the success of the group over the last four years:

- Digital database of the circumstances and opinions of over 600 women in cartography, survey and GIS from 42 member countries.

- Directory of Women in Cartography, Surveying and G1S, published 1993 (2nd Ed.1995). This contains data on 300 women from over 40 member countries and has already been used by the organising committees of the Cologne (1993) and Barcelona (1995) conferences, raising significantly, the participation of women in both.

- Organisation of training seminars given by women members of the group in Mexico, 1992 and as part of the ICA Seminar in Istanbul. 1994. Subjects presented included 'GIS and Expert Systems in Cartography' and 'Visualization, Hypermedia and Multimedia applications in 
Electronic Mapping'.

- Two Workshops on gender-related issues entitied 'The Role of Women in Technological Change' at the ICA Conference in Cologne, 1993.

- Contact with the IGU Commission on Gender and Geography and an invited paper given to the IGU Conference, 1992. The IGU Commission was so interested in the work in the ICA group that they set up a Permanent liaison between them.

- International recognition of the role of the Working Group was made through two invitations received from the UN to present papers at the 5th UN Cartographic Conference for the Americas. New York, 1993, and the 13th UN Regional Cartographic Conference for Asia and the Pacific, Beijing, 1994. An important resolution, proposed in that paper and passed by

the Conference, stated: "The Conference, acknowledging the important role women play in surveying, mapping and charting, and noting the under-representation of women at professional, educational conference and networking activities, recommends that the national survey, mapping and charting organisations create increased opportunities for women to attend such activities and create opportunities or women for career advancement".

This Working Group has contributed significantly by increasing professional development opportunities for the target groups.

Another active group with specific outreach in South America is the Commission on Tactile Mapping and Low-vision Mapping. To its general work in this field have been added closer links with the Committee on Access to Information and Culture of the World Blind Union to increase world-wide co-operation. Apart from Commission meetings held in Brazil and Cologne the most important achievement was the IVth International Symposium on Maps and Graphics for the Visually Impaired (Sao Paulo, Brazil, 1994) which proved to be a major breakthrough in establishing contacts and building enthusiasm throughout Latin America. Two workshops were organised in early 1995 (in Argentina and Northern Brazil) and more are proposed for Chile and Peru. The proceedings of this symposium are in course of publication and plans are being laid on the format for an atlas for children with a teachers' guide.

\section{SPECIAL THEMES}

Special themes pervade all the work of the ICA but this section focuses on two which are subject specific.

The Working Group on Marine Cartography is a large and enthusiastic assembly mainly of networked corresponding members. Although correspondence is the primary means of communication, five meetings have been heid in Battimore, Cologne, Norfolk VA, Monaco and Cork. Liaison has been established with the International Hydrographic Organisation, The Hyorographic Society and the IGU and maximum encouragement, through expert contacts and assistance with sources, is given to authors writing in the field. Promotion of the ICA and cartography as major contributors in the field of coastal zone management has been achieved in a number of ways:

- Preparation of a comprehensive review of the status of marine cartography.

- In co-operation with the IGU Commission on Coastal Systems, introduction of a successfut series of CoastGIS Symposia (e.g. in Norfolk, USA 1994 ; Cork, Ireland 1995) establishing the ICA as a leader in the fleld.

- Promotion of the coastal zone as an entity in the drive for digital data standards

A multi-lingual gazetteer of ocean names is on the agenda and papers have been authored by group members in the area of coastal zone cartography and data availability. The proceedings of the series of Conferences held since 1990 are in the process of publication.

The Commission on Cartography of Population Mobility: formed in 1991, has operated almost solely as a compact traditional-mail-networked group. Although within the theme of population mobility, the special problems selected for attention were the definitions of, and some suggested solutions to, mapping the size and location of intemational (transfrontier) and interregional (within country) population migration. Some of these have been explored but the objectives were later 
narrowed to examples only, selected from a wide range of mobility issues - local/regional to global, migration and refugee problems. A variety of population parameters were investigated. from country totals to data on tourist movements between countries. Results of research were presented at the Barcelona Conference in 1995. Perhaps unique to this report, the achievements of this Commission have included the compilation and production of coloured maps including the 1992, 1993 and 1994 editions of the map of world-wide distribution of humanitarian aid provided by the ECHO Programme (European Community Humanitarian Office, Brussels) and various other maps of refugees and displaced persons.

\section{MAPS, CHILDREN and the WORLD}

Barbara Petchenik, Vice-President of the $1 \mathrm{CA}_{1}$ who died in 1992, had a lifelong interest in maps for children. For this reason it was decided that a most appropriate memorial would be an Award for world maps created by children. The competition is open to children under 16 years of age who are invited to draw a map of the world on any theme of interest to them. Negotiations with UNICEF added value to the award. Winning entries would be accepted for consideration as designs for their famous Greetings Card range. Each member nation of ICA is asked to organise the competition and to select a maximum of five drawings according to its own criteria. The national winners are then forwarded to ICA and following display at an ICA conference, ten international winners are selected with at least one from each continent. 27 member nations participated in the first competition in 1993. Judging was dificult with the variety of artistic creations presented, and themes ranged from the traditional (peace and the environment) to individual impressions of the horrors of hunger, war, famine and pollution.

This initial UNICEF connection led to the incorporation of many of the children's maps into a United Nations CD-ROM called My City, which was in the exhibit at the world Summit on Social Development in Copenhagen in 1995 and subsequently travelled to New York and to the Women's Summit in Beijing in September 1995. My City is an interactive educational game for schools and children, which is based on the Convention of the Rights of the Child dealing with issues of culture, law, welfare, education, health and environment. The producer of the CD viewed all seventy finalist maps from the 1993 competition and incorporated over 20 of them into My City. My City is being distributed to schools in North America and Europe in August 1995 and the producers have indicated a desire to include maps from subsequent competitions into their products.

The maps have also attracted further interest. UNICEF Canada, as part of the lead agency for the United Nations Corvention on the Rights of the Child, and the ICA propose to develop an educational tool from the 1995 children's map competition in the form of a large colour wallsheet. Selected children's maps will represent their views of the world and the wallsheet will be used as a vehicle for children to express their concerns about pressing development issues and present altemative ways of looking at the worid. Although initially Canada-based, the intention is to extend this project to all UNICEF nations.

The ongoing efforts of the ICA to encourage the creation of maps by children may be the most significant achievement of the Association to date. Thousands of children have been involved and maps which have been neglected in the formal educational system of many nations are being reintroduced as a means of understanding, analysing and experiencing the most important international issues facing the world today.

\section{Conclusion}

The achievements presented here are important for a number of reasons. They are evidence of the energy and expertise of many people both leading and participating in the groups described. They shouid be of interest to cartographers in general as ICA people are mainly cartographers who have chosen to become involved in the wider mission of an international organisation. They 
only represent a stage in the continuing evolution of the ICA. Most Commissions continue their work from one 4-year session to the next, but new Commissions emerge, normally after a period as a Working Group. The next session is thus entiched by the presence of new Commissions on Theoretical Fields in Cartography, Visualization: Marine Cartography, and Gender and Cartography, and also embryo Commissions, in the form of new Working Groups on Map Generalisation, and Cartography and Children. Further suggestions for Working Groups are also on the agenda for the near future. There has been a tendency for grass-roots cartographers who are not directly involved in ICA activities to regard the organisation as 'remote' and even irrelevant to their everyday working lives. This is understandable as leading participants have frequently been senior staff and involvement can cost money for travel, etc. It is the author's wish that this feeling should fade and be replaced by one of awareness of being part of a world-wide 'family' with common aims and wishes. Atter all if you belong to one of the ICA's member nations then you are already a member of the organisation and could participate ! Corresponding membership of Commissions and Working Groups need not involve the costs of travel but can allow members to share their ideas and truly participate in discussion and decision-making. This kind of participation is even more rewarding today with electronic mail and the internet which can make you feel closer to the heart of things. Travel itself is rewarding but it is also good just to 'talk' to colleagues across the world. If you have useful opinions about the ICA and its activities or would like to become more closely involved please communicate with your national delegate/contact person (through the Secretary-General if necessery) or with the President. The greater the involvement by the wider 'mapping' scientific community the greater the strength of the ICA.

OFFICLAL PUBLICATIONS of the Imternational Cartographic Association for the period $1991-96$

Inventory of World Topographic Mapping, Volumes 2 and 3. Compiled by Rolf Böhme. English Language Editor Roger Anson, 1991 and 1993

Basic Cartography for students and technicians, Volume 1 (Second Edition). Edited by R.W. Anson, 1993

Basic Cartography for students and technicians, Volume 3, Editors R.W. Anson and F.J. Ormeling, 1996

Thematic Mapping from Satellite Imagery, a Guidebook. Edited by J Denegre, 1994

Elements of Spatial Data Quality. Editors S.C. Guptill and J.L. Morrison. 